\title{
OPEN Heat sensitivity of first host and cercariae may restrict parasite transmission in a warming sea
}

\author{
Dakeishla M. Díaz-Morales $\mathbb{1}^{1 凶}$, Claudia Bommarito², Jahangir Vajedsamiei², \\ Daniel S. Grabner ${ }^{1}$, Gil Rilov ${ }^{3,4}$, Martin Wahl' ${ }^{2}$ Bernd Sures ${ }^{1}$
}

To predict global warming impacts on parasitism, we should describe the thermal tolerance of all players in host-parasite systems. Complex life-cycle parasites such as trematodes are of particular interest since they can drive complex ecological changes. This study evaluates the net response to temperature of the infective larval stage of Himasthla elongata, a parasite inhabiting the southwestern Baltic Sea. The thermal sensitivity of (i) the infected and uninfected first intermediate host (Littorina littorea) and (ii) the cercarial emergence, survival, self-propelling, encystment, and infection capacity to the second intermediate host (Mytilus edulis sensu lato) were examined. We found that infection by the trematode rendered the gastropod more susceptible to elevated temperatures representing warm summer events in the region. At $22{ }^{\circ} \mathrm{C}$, cercarial emergence and infectivity were at their optimum while cercarial survival was shortened, narrowing the time window for successful mussel infection. Faster out-of-host encystment occurred at increasing temperatures. After correcting the cercarial emergence and infectivity for the temperature-specific gastropod survival, we found that warming induces net adverse effects on the trematode transmission to the bivalve host. The findings suggest that gastropod and cercariae mortality, as a tradeoff for the emergence and infectivity, will hamper the possibility for trematodes to flourish in a warming ocean.

Climate change-related temperature shifts are recognized as one of the main drivers of marine benthic community changes ${ }^{1-3}$. However, in realistic natural scenarios, climate change impacts should be addressed as a concert of multiple abiotic and biotic factors ${ }^{4-6}$. Biotic factors such as species interactions can have the capacity of buffering or amplifying climate change effects on individual species as well as on communities (e.g. Ref. ${ }^{7}$ ). Thus, to more realistically predict climate change impacts on species or communities, we need to describe the respective thermal tolerance of closely interacting species systems. Host-parasite systems are one example of such interacting systems that, in response to temperature, can result in complex ecological changes ${ }^{8-12}$. Moreover, as many free-living species are infected with at least one specific parasite species ${ }^{13,14}$, host-parasite interactions are among the most intimately interspecific interactions in ecology. Thus, parasites have to be considered in studies of climate change effects as an important group of biotic drivers. In other words, understanding the fate of host-parasite systems in the context of global warming is crucial and demands consideration of the thermal sensitivity of various life-cycle stages of the involved species.

Trematode parasites are of particular interest in the context of global warming due to their complex life cycle, which often includes three hosts: a first intermediate host (usually a gastropod), a second intermediate host (e.g., crustaceans, fish, bivalves, amphibians), and a final host (often a vertebrate such as shorebirds ${ }^{15}$ ). Such a complex life cycle poses a severe constraint to trematode populations faced with global warming due to two main reasons. First, the absence of a single required host group will directly result in the excision of the parasite from the community in question. Second, the life cycle includes free-living larval stages (i.e., miracidia and cercariae) directly, and potentially differentially, influenced by multiple abiotic and biotic factors from the external environment ${ }^{16,17}$.

Cercariae have been long known to be sensitive to temperature and one of the most fragile components of the trematode life cycle ${ }^{17,18}$. Their survival and self-propelling capacity, for example, are highly constrained by warm temperatures due to the lack of feeding ability and, thus, rapid depletion of energy reserves at warmer temperatures ${ }^{18}$. However, an increase in temperature can benefit other traits such as cercarial emergence and

\footnotetext{
${ }^{1}$ Aquatic Ecology and Centre for Water and Environmental Research, University of Duisburg-Essen, Essen, Germany. ${ }^{2}$ Benthic and Experimental Ecology Department, GEOMAR, Helmholtz Centre for Ocean Research, Kiel, Germany. ${ }^{3}$ Israel Oceanographic and Limnological Research, National Institute of Oceanography, P.O. Box 8030, 31080 Haifa, Israel. ${ }^{4}$ Marine Biology Department, The Leon H. Charney School of Marine Sciences, University of Haifa, Mt. Carmel, 31905 Haifa, Israel. ${ }^{\circledR}$ email: dakeishla.diaz-morales@uni-due.de
} 


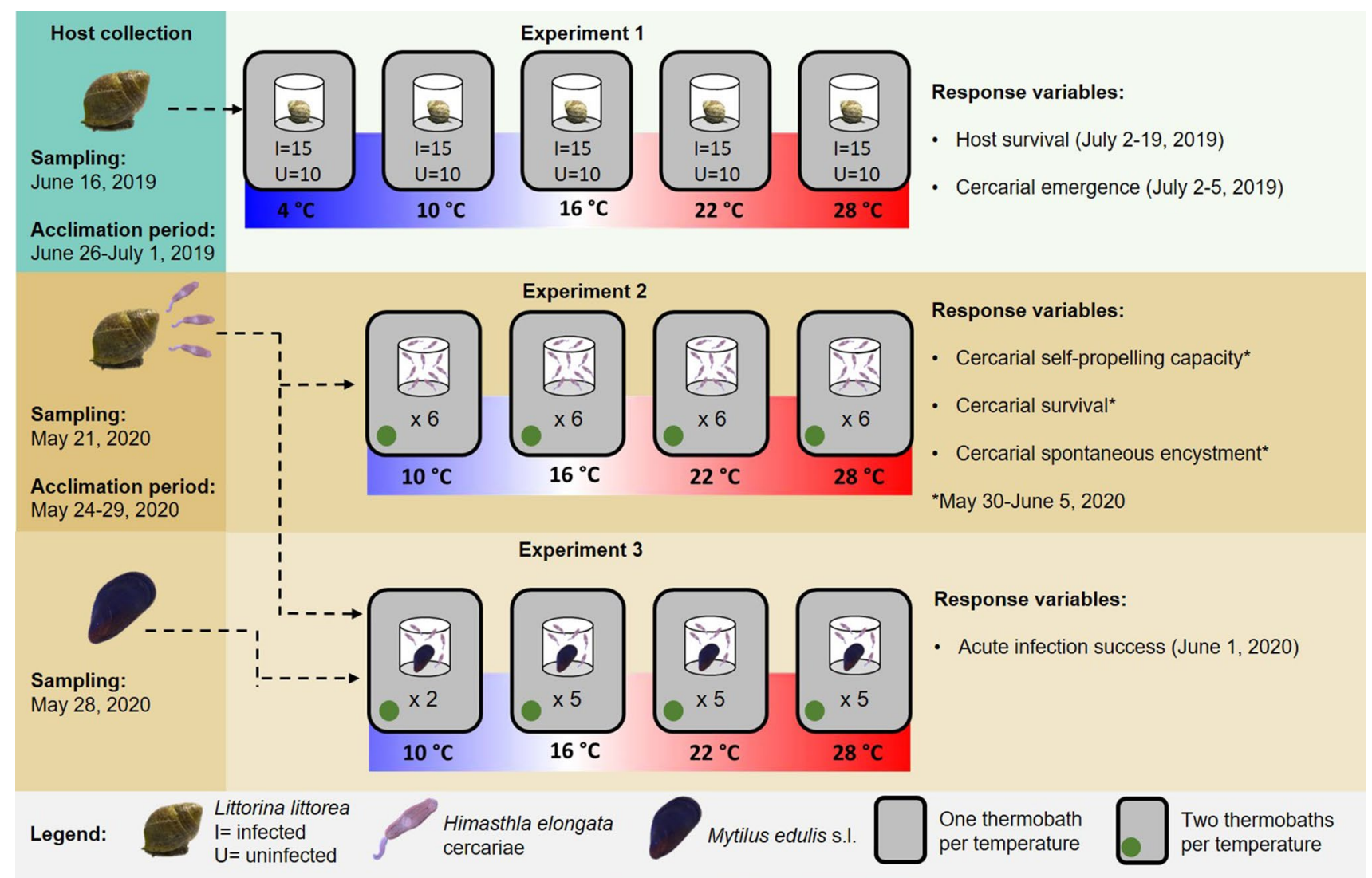

Figure 1. Schematic representation of the experimental design. In Experiment 1, the survival of infected and uninfected Littorina littorea was evaluated along with cercarial emergence at $4,10,16,22$, and $28^{\circ} \mathrm{C}$. In Experiment 2, the performance of cercariae at $10,16,22$, and $28^{\circ} \mathrm{C}$ was assessed by evaluating their self-propelling capacity and survival and encystment rates. In Experiment 3, acute infection success of Himasthla elongata to Mytilus edulis s.l. was evaluated at $10,16,22$, and $28^{\circ} \mathrm{C}$.

infectivity ${ }^{19,20}$. The observations on this thermally-induced tradeoff in favor of higher emergence and infectivity previously suggested that trematode infections will increase in a warming environment ${ }^{9,19,20}$. However, growing evidence has shown that the matter is more complicated than previously envisioned, mainly due to important factors such as the hosts' sensitivity to abiotic stressors, the phenology timeline of both hosts and parasites, and the parasites' species-specific idiosyncrasy $6,10,21-28$.

Considering the first intermediate host's performance in response to temperature is essential to understand the fate of trematodes under global warming. Trematodes show a high specificity for their first intermediate host ${ }^{15,29}$. This high specificity results in reduced flexibility when searching for appropriate hosts. Even though first intermediate hosts (e.g., gastropods) inhabiting intertidal zones are evolutionarily adapted to stressful environments, even these eurytherms may already live close to their limits of thermal tolerance, and prolonged exposure to heat and recurrent heatwaves can push them over the edge ${ }^{30}$. The heat sensitivity of first intermediate hosts can be amplified when they are infected by trematode parasites, especially by castrating parasite species, which can take a considerable toll on its host's thermal sensitivity ${ }^{31}$. Hence, the parasites' greater production of transmission stages could be offset by increased mortality of the first host in warming oceans.

Therefore, to understand the net effect of global warming on host-parasite interactions, it is necessary to consider the most fragile components of the life cycle of trematodes, such as the cercariae and the first-intermediate host. Using Himasthla elongata (Mehlis, 1831) and its intermediate hosts from the Western Baltic Sea as a model system, this study experimentally assessed the impacts of temperature on (i) the survival of infected versus uninfected first intermediate host (i.e., the snail Littorina littorea (Linnaeus, 1758)) and (ii) the emergence of H. elongata cercariae along with their self-propelling capacity, survival, encystment, and infectivity to the second intermediate host (i.e., the Baltic Mytilus edulis sensu lato (Linnaeus, 1758); Fig. 1). The temperatures tested (4, $10,16,22$, and $28^{\circ} \mathrm{C}$ ) represent the range of temperatures expected to be relevant to the performance of the parasite ${ }^{20}$, and include projected end-of-century summer thermal averages and current summer heatwave events in the summer in the Baltic Sea $\left(22^{\circ} \mathrm{C}\right)^{32-34}$, as well as an extreme temperature scenario $\left(28^{\circ} \mathrm{C}\right)$. Specifically, we tested whether the vulnerability of the cercariae and (infected) gastropod host to high temperatures can set a limit on the heat-induced proliferation of the trematode infection to mussels. 


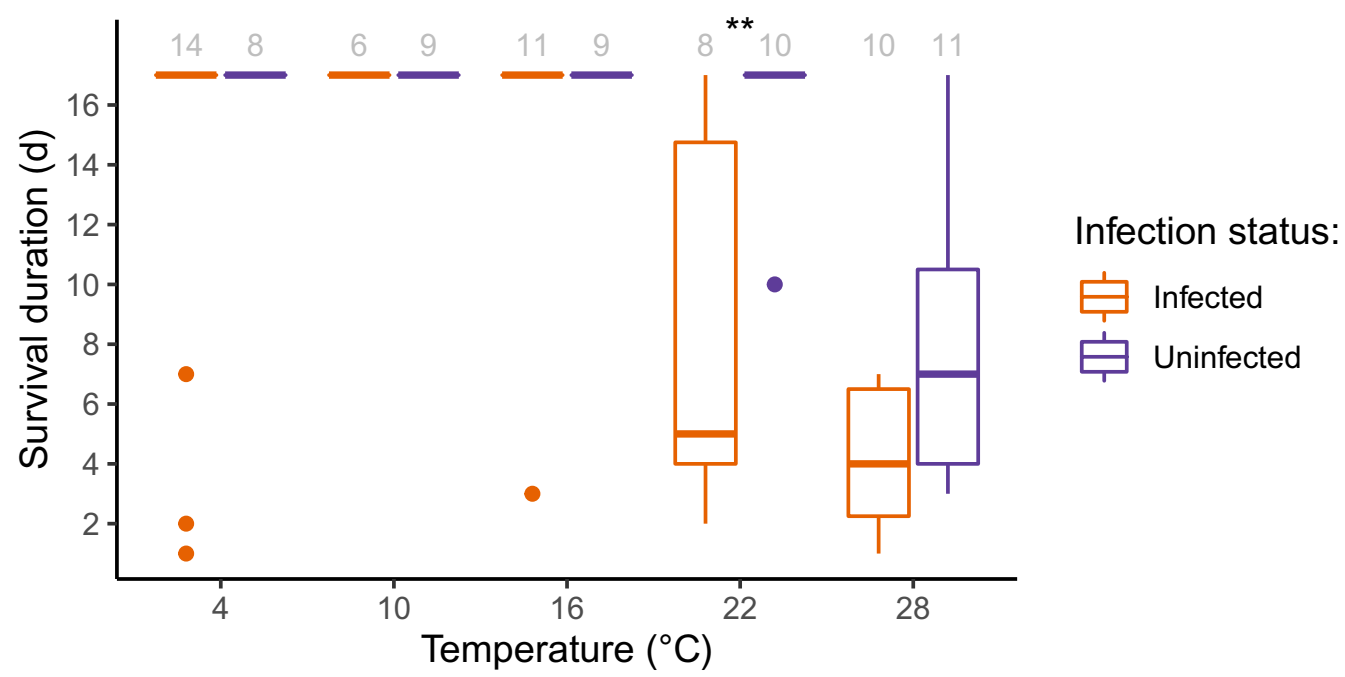

Figure 2. Survival duration of Littorina littorea uninfected and infected by Himasthla elongata after a 17-day post-acclimation exposure to different temperatures. Asterisks represent significant differences between infected and uninfected individuals (Mann-Whitney-U-Test, Holm-corrected $\mathrm{p}<0.01$ ). Gray numbers represent sample sizes.

\section{Results}

Experiment 1a: General host infection status and survival. From the initial 125 snails, $82 \%$ survived the acclimation period. Specifically, $94 \%$ of the uninfected snails survived as compared to $76 \%$ of the infected snails. This left us with a total of 102 snails for Experiment 1, from which $54 \%$ were infected by trematodes. Among the infected snails, $11 \%$ were infected with Renicola roscovita and $89 \%$ with $\mathrm{H}$. elongata, and no coinfections were detected. Statistical analyses were performed only for snails infected with $H$. elongata since the number of specimens infected by $R$. roscovita was too low to conduct meaningful comparisons. At the beginning of the experiment, $96 \%$ of the infections with $H$. elongata were patent (i.e., emergence of cercariae detected), which changed to $74 \%$ at the end of the experiment. At the end of the experiment, the percentage of patent infections was lowest at $4{ }^{\circ} \mathrm{C}\left(18 \%\right.$ of the snails) followed by $10{ }^{\circ} \mathrm{C}$, where $80 \%$ of the infected snails presented patent infections. Above $16^{\circ} \mathrm{C}$, patency was higher than $88 \%$. Once acclimatized, L. littorea generally died faster at 22 and $28^{\circ} \mathrm{C}$ than at colder temperatures (Fig. 2). Snails infected by H. elongata survived less than uninfected ones, mainly at $22^{\circ} \mathrm{C}$, where significant differences were detected (Mann-Whitney-U-Test, $\mathrm{p}<0.01$ ). At $28^{\circ} \mathrm{C}$, mortality was high in both infected and non-infected snails. However, survival of uninfected individuals was slightly higher (survival range: 3-17 days; Fig. 2), although not significant due to high variability.

Experiment 1b: Emergence of Himasthla elongata cercariae. The emergence of cercariae was significantly affected by temperature (2nd-degree polynomial: $\mathrm{p}<0.001, \mathrm{t}=-5.34 ; \mathrm{df}=38, \mathrm{R}^{2}=0.85$; Fig. 3A, see Supplementary Table S1). The optimal temperature for cercarial emergence was $22.7^{\circ} \mathrm{C}$ with an estimated mean of 938 (702-1257) cercariae per snail or 313 (234-419) cercariae per snail per day, which decreased on average by $30 \%$ at $28^{\circ} \mathrm{C}$ in comparison to $22^{\circ} \mathrm{C}$ (Fig. $3 \mathrm{~A}$ ). Almost no emergence was detected at $4{ }^{\circ} \mathrm{C}$. A significant positive linear relationship in response was detected between emerged cercarial encystment and temperature with the highest encystment rate detected at $28^{\circ} \mathrm{C}(38 \%)$ and zero values below $16^{\circ} \mathrm{C}\left(\mathrm{p}<0.001 ; \mathrm{Z}=6.78, \mathrm{R}^{2}=0.78\right.$, $\mathrm{DF}=38$; see Supplementary Table S1 and Supplementary Fig. S1). When correcting cercarial emergence for the survival of snails in each temperature, a negative shift in the optimal temperature by almost $4{ }^{\circ} \mathrm{C}$ was observed (Fig. 3B).

Experiment 2: Self-propelling capacity, survival, and encystment of Himasthla elongata cercariae. For all the response variables, the nonlinear smooth terms for temperature and time, as well as the tensor product interaction of time and temperature, were significant $(\mathrm{p}<0.0001$, GAMM $t$-statistic; see Supplementary Table S2). For mortality the time and temperature tensor product interaction was significant to a lesser degree ( $<<0.01$, GAMM $t$-statistic; Fig. 4B; see Supplementary Table S2). Regarding cercarial self-propelling capacity, a decrease in a sigmoidal manner was observed across time, while increasing temperatures accelerated this decrease (Fig. 4A). The whole model explained $87 \%$ of the variance in activity $\left(\mathrm{R}^{2}=0.872\right.$; see Supplementary Table S2). For $28^{\circ} \mathrm{C}$ the calculated $\mathrm{ET}_{50}$ was of $2.96 \mathrm{~h}(2.56-3.35 \mathrm{~h})$, for $22^{\circ} \mathrm{C}$ it was $4.46 \mathrm{~h}(3.98-4.77 \mathrm{~h})$, for $16^{\circ} \mathrm{C} 6.31 \mathrm{~h}(5.95-6.70 \mathrm{~h})$, and for $10^{\circ} \mathrm{C} 10.65 \mathrm{~h}(9.98-11.28 \mathrm{~h})$. Moreover, at both $28^{\circ} \mathrm{C}$ and $22^{\circ} \mathrm{C}$, the selfpropelling capacity ceased completely after $8 \mathrm{~h}$, while at $16^{\circ} \mathrm{C}$ and $10^{\circ} \mathrm{C}$ cercariae ceased to be active after $10 \mathrm{~h}$ and $14 \mathrm{~h}$, respectively. In terms of mortality, an increasing trend was observed across time, and temperature with $85 \%$ of the variance explained by the GAMM (Fig. $4 \mathrm{~B}$ ).

Similar to cercarial self-propelling capacity, the increase in mortality along time was enhanced by temperature. Specifically, the estimated half-life of cercariae $\left(\mathrm{LT}_{50}\right)$ was $21.88 \mathrm{~h}(18.28-25.33 \mathrm{~h})$ at $28^{\circ} \mathrm{C}, 37.57 \mathrm{~h}$ 

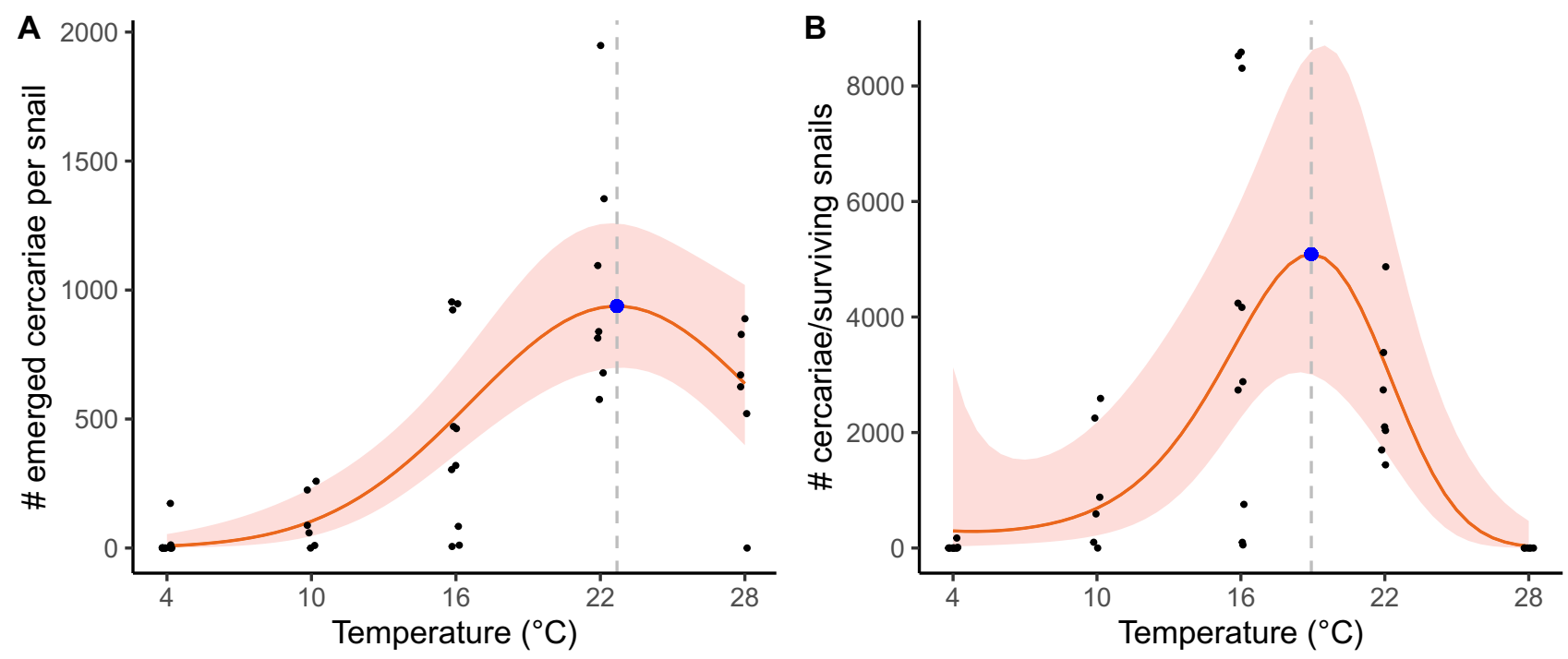

Figure 3. Cercarial emergence per snail (A) and net cercarial emergence per snails that survived from an initial population of 10 snails (B) over a 3-day incubation experiment in different temperatures. Regressions are based on generalized linear models with distributions of overdispersion-corrected Poisson (A) and zeroinflated negative binomial (B). The blue dot represents the optimal temperature $\left[22.7^{\circ} \mathrm{C}(\mathbf{A})\right.$ and $\left.18.9^{\circ} \mathrm{C}(\mathbf{B})\right]$ for cercarial emergence [ 938 cercariae per snail (A) and 5088 cercariae per survived snails (B)].

$(33.82-42.03 \mathrm{~h})$ at $22^{\circ} \mathrm{C}$, and $76.71 \mathrm{~h}(70.67-81.90 \mathrm{~h})$ at $16^{\circ} \mathrm{C}$. At $10^{\circ} \mathrm{C}$, maximum mortality of $9 \%$ was observed at $96 \mathrm{~h}$ with cercariae at this temperature surviving up to $120 \mathrm{~h}$. Finally, pre-mortem encystment of cercariae followed a more complicated pattern. At the warmest temperatures $\left(22\right.$ and $\left.28{ }^{\circ} \mathrm{C}\right)$, cercariae started encysting earlier but reached an estimated mean encystment rate of $27 \%(22-31 \%)$ and $18 \%(13-23 \%)$, respectively (Fig. 4C). Meanwhile, cercariae at $16^{\circ} \mathrm{C}$ started to encyst later on but reached a higher encystment proportion of $37 \%(32-42 \%)$. At $10{ }^{\circ} \mathrm{C}$, almost no encystment was observed with an estimated mean of $8 \%(3-14 \%)$. Moreover, the optimal temperature for cercariae pre-mortem encystment decreased over time (see Supplementary Fig. S2). In the case of pre-mortem encystment, the model explained $78 \%$ of the variance.

Experiment 3: Infection success. Both gross and net infectivity significantly correlated with temperature in a bell-shaped curve (Fig. 5A,B). For acute infection success, the nonlinear smooth term of temperature was significant $\left(\mathrm{p}<0.0001\right.$, see Supplementary Table S3). The whole model explained $47 \%$ of the variance $\left(\mathrm{R}^{2}=0.469\right.$; see Supplementary Table S3). The estimated optimal temperature for infection success was $21.5^{\circ} \mathrm{C}$, with an estimated mean of 45 (30-57)\% (Fig. 5A). In terms of organ partitioning, cercariae encysted mostly in the mussel's foot at 10,16 , and $22^{\circ} \mathrm{C}$. Encystment in the mantle was recorded in all temperatures, but it was highest at $22^{\circ} \mathrm{C}$. Encystment in other organs (e.g., adductor and retractor muscles, and intestine) was highest at $22^{\circ} \mathrm{C}$ and minimal in the other temperatures. Regarding the gills, no change in encystment was observed among temperatures except for $28{ }^{\circ} \mathrm{C}$ where encystment in the gills was absent. At this temperature $\left(28{ }^{\circ} \mathrm{C}\right)$, infection success was the lowest, and only the foot, the mantle, and muscles were infected without any clear difference among these organs. When considering cercarial emergence and the effect that temperature-specific gastropod survival has on cercarial emergence, the optimal temperature for net infective cercariae was reduced by $1.7^{\circ} \mathrm{C}$, with an estimated number of infective cercariae from surviving snails of 1933 (Fig. 5B). For this model, all terms (i.e., first-, second- and third-degree terms) were significant ( $\mathrm{p}<0.0001$, GLMM $z$-statistic; see Supplementary Table S3).

Summary: log response ratios. When comparing the treatments to the baseline temperature of $16^{\circ} \mathrm{C}$ we can see a differential response of $H$. elongata life cycle stages to temperature (Fig. 6). Specifically, the treatment of $22^{\circ} \mathrm{C}$ was beneficial to cercarial gross emergence, infection success, and net infectivity. In contrast, this treatment decreased survival of infected gastropods, net cercarial emergence, and cercarial self-propelling capacity from $4 \mathrm{~h}$ onwards. The $28^{\circ} \mathrm{C}$-treatment was detrimental for all traits except for cercarial emergence and activity at $2 \mathrm{~h}$, where the effect was almost neutral (Fig. 6). At $10^{\circ} \mathrm{C}$ most traits were unaffected except for net infectivity, which was reduced, and cercarial self-propelling at $8 \mathrm{~h}$, which was greatly enhanced. At $10^{\circ} \mathrm{C}$, no log-response ratio for cercarial emergence was reported since the Geary index suggested by Lajeunesse ${ }^{35}$ was below three. For the self-propelling capacity of cercariae, only the first eight hours are shown since, after this time, the larvae usually lose their self-propelling capacity.

\section{Discussion}

The present study illustrates that the first intermediate host (i.e., gastropod) and cercariae represent a fragile link in the life cycle of trematodes under current extremely warm events and projected end-of-century mean temperatures for temperate systems during summer ${ }^{36}$. The ubiquity of trematodes in the environment and their 

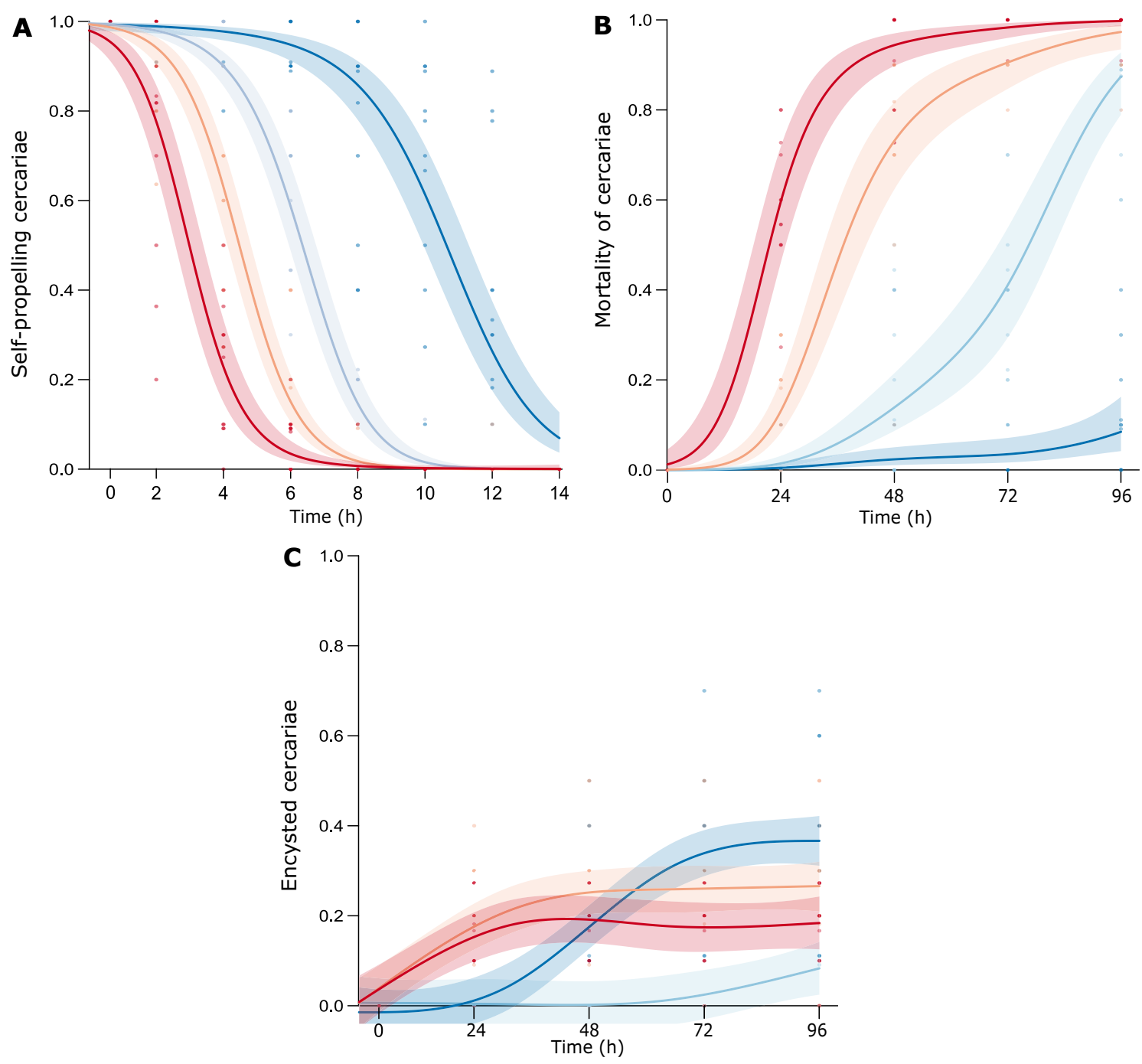

Figure 4. Generalized additive mixed models of Himasthla elongata cercariae activity (A), mortality (B), and encystment $(\mathbf{C})$ with temperature $\left({ }^{\circ} \mathrm{C}\right)$ and time $(\mathrm{h})$ as smooth terms. Models explain $87 \%$, $85 \%$, and $78 \%$ of the response variance, respectively.

capacity of modulating complex ecological systems makes their consideration in global warming effects predictions an urgent task. The studied $H$. elongata host-parasite system is a good example of the complex dynamics between closely interacting species such as the trematodes and ecologically relevant benthic species (e.g., the common periwinkle, L. littorea, and the blue mussel, M. edulis s.l.) under the influence of thermal stress. Our results conclusively showed that the optimal temperature range of parasite performance might be overestimated when looking at individual life cycle components. The infected gastropod's thermal sensitivity and reduced functional lifespan and survival of the cercariae resulted in a decreased overall performance of the parasite with temperatures above the thermal optimum of the host snail.

The trematode-induced gastropod thermal sensitivity is of significant ecological relevance under current and projected thermal regimes for temperate ecosystems as such gastropods play a major ecological role as grazers in their ecosystem. The infected gastropods show substantial mortality already after a few days (i.e., 1-7 days) of exposure to temperatures of $22^{\circ} \mathrm{C}$, projected as mean summer values for the region for the end-of-century ${ }^{32}$, as opposed to uninfected individuals which had no mortality at this temperature, and only started to die after three days exposure to $28{ }^{\circ} \mathrm{C}$. Current summer heatwaves in shallow water Baltic Sea habitats can reach up to $22{ }^{\circ} \mathrm{C}$ or even higher for several days ${ }^{32,34}$. This means that even the projected average summer temperatures will be stressful for infected gastropods. Although littorinids are assumed to be resistant to harsh conditions due to their evolutionary history in extreme environments ${ }^{37-39}$, exposure to other stressors (e.g., pathogens) could be fatal to them. 

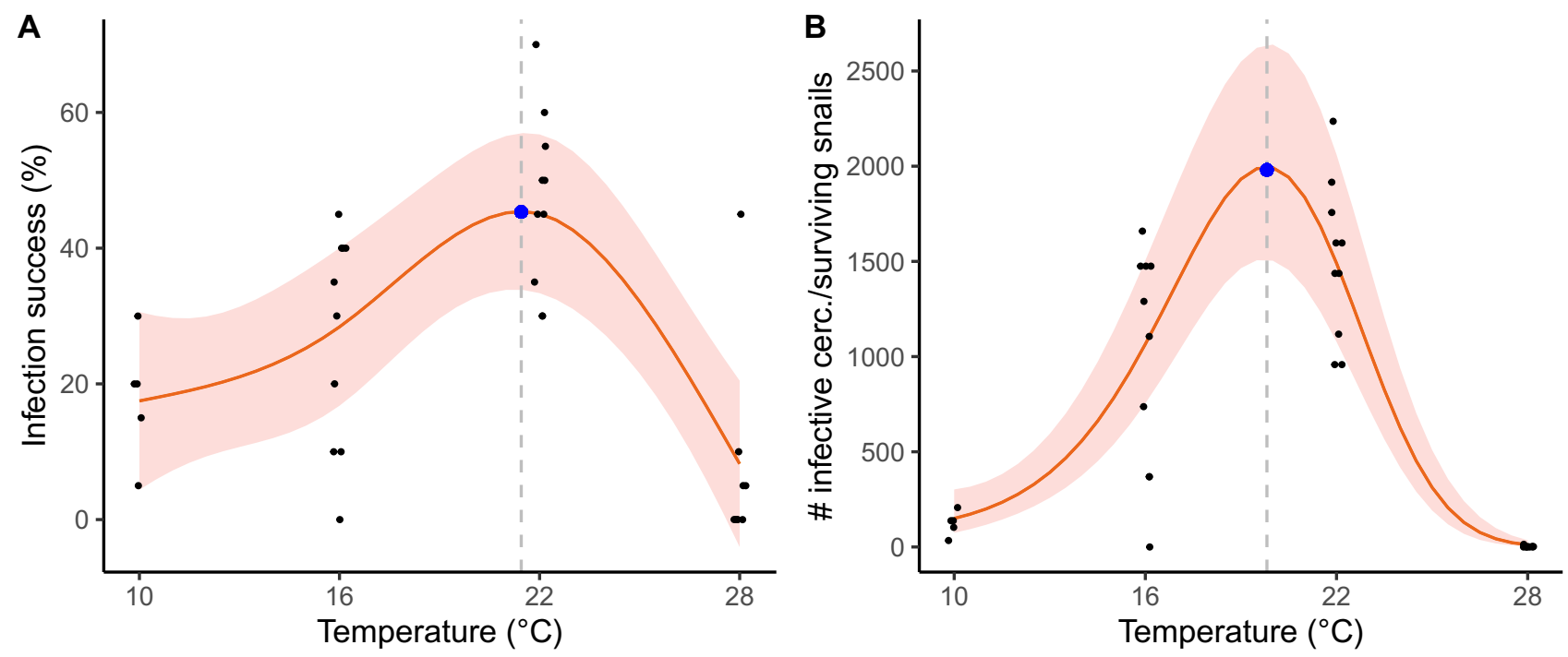

Figure 5. General additive mixed model of Himasthla elongata cercarial acute infection success (A) and generalized linear mixed model of cercarial net infectivity (B) after $24 \mathrm{~h}$ of exposure to Mytilus edulis s.l. under different temperatures with gaussian (A) and zero-inflated negative binomial (B) distributions. The blue dot represents the optimal temperature $\left[21.5^{\circ} \mathrm{C}(\mathbf{A})\right.$ and $\left.19.8^{\circ} \mathrm{C}(\mathbf{B})\right]$ for cercariae infectivity [45\% infectivity (A) and 1933 infective cercariae from surviving snails $(\mathbf{B})]$.

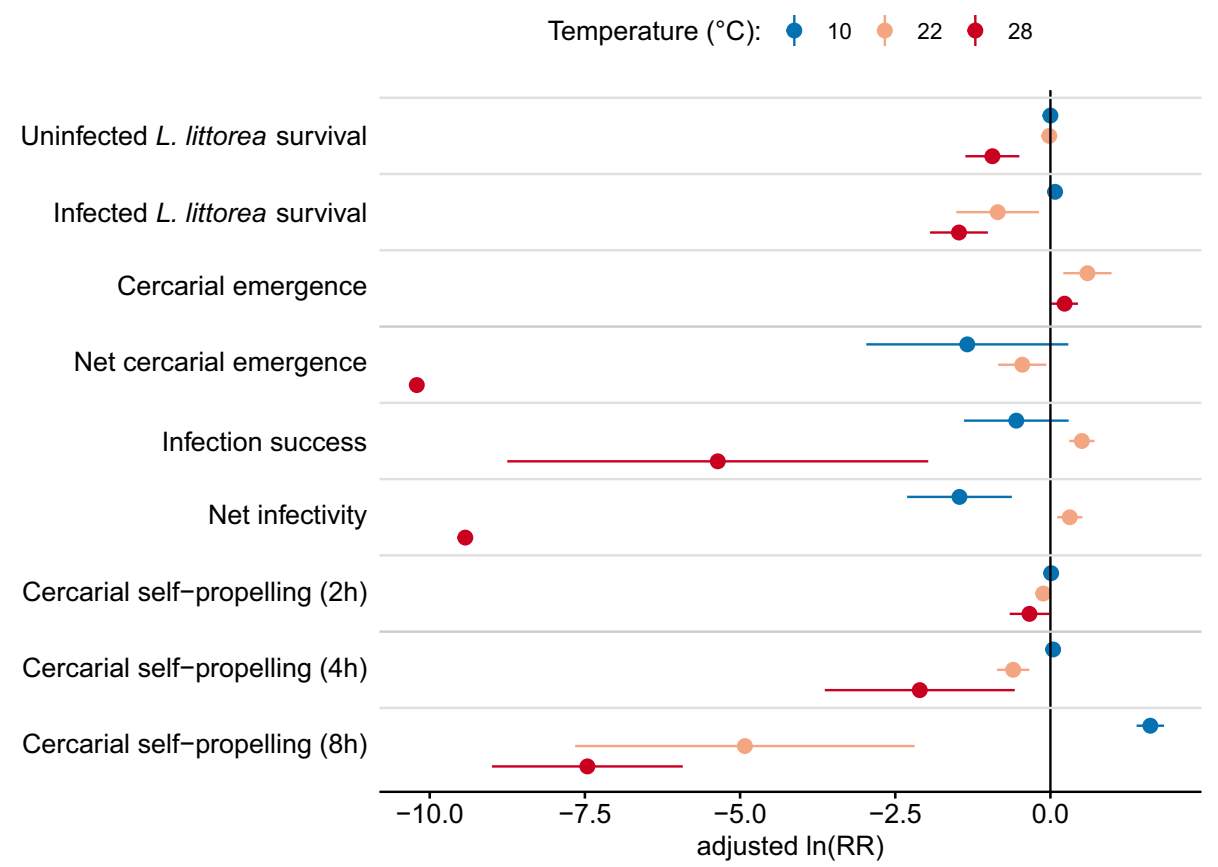

Figure 6. Logarithmic response ratios for crucial traits of the Himasthla elongata life cycle in response to temperature deviations. Ratios were calculated and adjusted to small sample sizes according to Lajeunesse ${ }^{35}$ in relation to the baseline temperature of $16^{\circ} \mathrm{C}$. The means of the control temperature for each trait were estimated from the models described in the methods section. Values are given as means and confidence intervals $(\alpha=0.05)$.

Trematodes pose significant stress to their gastropod host in many ways. First, they are known to castrate their host by chemical interference of the host's endocrine system and physical destruction in mature infections ${ }^{31}$. Also, cercarial emergence can severely damage the host tissue since they migrate through the skin of the gastropod ${ }^{31}$. Enhanced gastropod mortality by parasites has already been observed for other trematodes. McDaniel ${ }^{40}$ showed that L. littorea infected with the trematode Cryptocotyle lingua have a reduced heat tolerance. In warm temperatures, infected snails show more mature and heavier infections, while at cold temperatures, infection intensity is reduced, and relatively small rediae can be observed (personal observation). Since higher temperatures can 
accelerate the development of infections ${ }^{41}$, snails might benefit from colder temperatures where infection development is arrested and poses less stress to the host.

The parasite-enhanced mortality and decreased overall fitness have been observed both in the marine environment and freshwater ecosystems ${ }^{42-44}$. Paull and Johnson ${ }^{42}$ showed that the freshwater trematode Ribeiroia ondatrae increased its pathology with warmer temperatures by reducing fecundity in the gastropod Planorbella trivolvis (previously Helisoma trivolvis). In the same host-parasite system, Paull et al.$^{43}$ showed that infection by $R$. ondatrae increased snail mortality both before and after temperature shifts. These effects of trematodes on their gastropod host can go beyond the individual level and can result in a cascade of effects that compromises the structure and functioning of communities ${ }^{45}$. In the case of $H$. elongata, the prevalence of infection has been reported up to $40 \%$ in the southwestern Baltic Sea ${ }^{46}$. A high prevalence of infection combined with decreased thermal tolerance could translate into two possible (mutually non-exclusive) scenarios. First, in the near future, infection plus high temperatures could provoke a significant decrease in gastropod populations and, therefore, the scarcity of a functionally important organism on rocky shores. In the long run-bearing in mind the castrating behavior of $H$. elongata-it could provoke an evolutionary advantage for gastropod populations since thermal stress would select for uninfected (i.e., non-castrated) thermal tolerant individuals which can contribute to the reproduction and persistence of the species.

Acute infection success was also optimal at $22{ }^{\circ} \mathrm{C}$. Higher infectivity with higher temperature has been reported for many cases in the literature for both laboratory and field experiments $\mathrm{s}^{20,47-49}$. Increasing temperatures accelerate the metabolism of cercariae, providing more ATP for penetrating the host tissue and establishing as metacercariae $e^{15,48}$. The infectivity of trematode larvae can also be compromised by a reduction in the filtering activity of the musse ${ }^{50}$. Himasthla elongata targets primarily the foot and the mantle of the mussel, which are usually exposed when the mussel is open. In our case, after offering the cercariae to the mussel, most of them were open with their mantle and foot exposed, except for one mussel at $16^{\circ} \mathrm{C}$ and one at $28^{\circ} \mathrm{C}$. Mussel filtration rate has been demonstrated to remain stable up to $24^{\circ} \mathrm{C}$, and beyond this temperature, substantial metabolic depression has been observed ${ }^{51}$. Our data sustain this fact since the infection of the gills remained relatively constant between 10 and $22^{\circ} \mathrm{C}$. Therefore, in our experiment, infectivity might be affected by reduced mussel filtration only at temperature $28^{\circ} \mathrm{C}$.

Reduced activity and survival with increased temperature and time were not a surprise. Previous literature has shown that activity and survival of continuously swimming cercariae are limited to a few hours due to their lecithotrophic character ${ }^{52}$. The inability to feed makes glycogen (the primary energy reserve for cercariae) a limiting factor. Therefore, higher metabolic rates enhanced by warmer temperatures will deplete the energy reserve faster, which manifests into faster loss of activity and, ultimately, death ${ }^{18}$. Accelerated death can be observed when comparing the half-life $\left(\mathrm{ET}_{50}\right)$ of cercariae, which at $28^{\circ} \mathrm{C}$ was almost four times lower than at $16^{\circ} \mathrm{C}$. In terms of self-propelling capacity, the $\mathrm{ET}_{50}$ values were three times lower at $28^{\circ} \mathrm{C}$ than at $16^{\circ} \mathrm{C}$. Self-propelling capacity resulting in an efficient displacement in the water column is an important trait for trematode overall performance. Since himasthlids do not use chemotaxis and do not search actively for a host, they rely on other important factors aiding transmission ${ }^{50,53}$. Such factors include displacement in the water column via self-propelling, phototactic behavior, positive geotropism, which naturally attracts them to benthic invertebrates (i.e., bivalves), and the siphon current from the host itself ${ }^{29,50}$. In this experiment, the capacity for self-propelling generally lasted longer than expected, especially at lower temperatures $\left(10^{\circ} \mathrm{C}\right)$, where cercariae were self-propelling for up to $14 \mathrm{~h}$, although they were displacing themselves very slowly (personal observation). Therefore, conducting behavioral studies that characterize cercariae movement patterns (e.g., swimming velocity and distance moved) in response to temperature might be complementary to self-propelling capacity as indicators of infectivity ${ }^{54}$.

In Experiment 1b, we initially observed increases in the proportion (maximum $40 \%$ ) of cercariae spontaneously encysted with increasing temperatures. For the marine trematode species H. elongata, this type of encystment occurs typically in less than $1 \%$ of the cercariae ${ }^{55,56}$, and the factors inducing this type of encystment have not been elucidated yet. Only two studies reported higher in vitro spontaneous encystment in the presence of hemolymph and plasma extracted from mussels ${ }^{55,57}$. However, these factors are only relevant when the cercariae are inside the mussel. In our case, after closely evaluating encystment and mortality rates as a response to time and temperature (i.e., Experiment 2), we can see that cercariae were not only encysting faster but were also dying faster. Therefore, encystment without the presence of the second intermediate host (i.e., spontaneous encystment) seems to be a before-death response. We thus suggest the term pre-mortem encystment as a more accurate term to describe this aspect of the life cycle.

Pre-mortem encystment could be useful for the parasite when the second intermediate host is not present. Instead of merely dying, the cercariae transforms into metacercariae, extending the larvae's lifetime for up to $48 \mathrm{~h}$ (personal observation). However, reaching the final host in this way is very unlikely. This reduced probability is attributed to the fact that shorebirds get infected more likely when feeding on infected bivalves than when accidentally ingesting metacercariae directly from seawater ${ }^{58}$. Moreover, this external cyst has a thicker impermeable layer that protects against external stressors ${ }^{15}$. A thicker layer does not offer the same advantages as the cyst formed in the bivalve tissue, which has a thinner permeable layer that allows for obtaining nutrients from the host ${ }^{15}$. Another interesting observation was that, even though the cercariae were encysting faster at higher temperatures, the maximum encystment proportion was observed at $16^{\circ} \mathrm{C}$. At higher temperatures, pre-mortem encystment might be hindered by enhanced metabolism leading to a faster loss of energy reserves ${ }^{59}$. The formation of the multiple layers of the cyst requires energy-costly metabolic processes ${ }^{15}$. Similar results were found by Fried and Ponder ${ }^{60}$, who evaluated in vitro encystment of the freshwater echinostome Echinostoma caproni at $12,23,28$, and $37.5^{\circ} \mathrm{C}$. The authors of this study found that maximum encystment in artificial media (Locke's medium mixed with artificial pond water in a $1: 1$ ratio) was reached at $23^{\circ} \mathrm{C}$ with $78.2 \%$ of the cercariae encysted, while at $28{ }^{\circ} \mathrm{C}$ it decreased to $43.8 \%$ and to $0 \%$ at the maximum temperature. 
When looking at life cycle components individually, we could hypothesize that trematode transmission might be facilitated in current summer heatwave events and end-of-century temperature scenarios $\left(22^{\circ} \mathrm{C}\right.$ for the Baltic during the summer). Cercarial emergence and infectivity were optimal near this temperature $\left(22.7^{\circ} \mathrm{C}\right.$ for the emergence and $21.5^{\circ} \mathrm{C}$ for infectivity). Nevertheless, this assumption might not hold true for three reasons. First, even though we see a peak of emergence and infectivity, the optimal temperature range is approximately $3-6^{\circ} \mathrm{C}$ wide (i.e., optimum between ca. $19-25^{\circ} \mathrm{C}$ ). The stability of cercariae over a wide thermal range at its optimum has been recently explored and challenges the previous assumption that temperature is the most determinant abiotic factor in the transmission of parasites ${ }^{48,61,62}$. Nevertheless, since the amount of data gathered in this experiment does not allow for an accurate estimation of the optimal temperature range via means of bootstrapping or posterior inference, we highlight the importance of testing the same range of temperatures with higher resolution (i.e., more temperatures). Second, after adjusting cercarial emergence and infectivity to the parasite- and temperatureinduced mortality of the gastropod host, we can see that the optimal temperature for emergence and infectivity is shifted to lower temperatures resulting in a costly tradeoff. Specifically, trading first intermediate host survival for higher cercarial emergence as a response to global warming (i.e., prolonged exposure to $22^{\circ} \mathrm{C}$ ) translates into approximately $41 \%$ of loss in net cercarial emergence and $25 \%$ of loss in net infectivity in comparison to optimal conditions (i.e., $19^{\circ} \mathrm{C}$ ). Therefore, this disparity between the thermal performance of the host and the parasite is unstable ground and could translate into a collapse of the host-parasite system overall, as evidenced in other host-parasite systems ${ }^{10}$. The third reason why trematodes will not necessarily benefit from warmer temperatures is the energetic cost that warming implies for the cercariae. Increasing temperature accelerates the loss of selfpropelling capacity and death of cercariae, thus tightening the time window at which cercariae are infective. At $22^{\circ} \mathrm{C}$-temperature representing current summer heatwave events and end-of-century projected averages for the Baltic-the half-functional lifespan of cercariae is only $4 \mathrm{~h}$. With mussel beds declining in biomass due to climate change and displacement by invasive species ${ }^{63,64}$, a narrow infective time window represents an obstacle for transmission since a decline in blue mussel populations reduces the probability of cercariae reaching the bivalve host in time before losing infection potential and their chance to continue the life cycle.

Although the overall prognosis for trematode infections in a warming sea does not seem to be auspicious, other scenarios might hold probable. For example, since temperatures are expected to increase gradually until the projected end-of-century scenario is reached, summer thermal averages might initially benefit the parasite in upcoming years. In other words, before we reach a summer thermal average of $22^{\circ} \mathrm{C}$, colder thermal averages (i.e., $18-21^{\circ} \mathrm{C}$ ) might benefit the parasite initially, and only after, net adverse effects should be expected. Moreover, global warming might create appropriate conditions in seasons that (currently) might be too cold for parasites to proliferate (i.e., in winter). Therefore, we might expect a shift in the season of high infection development and activity instead of an apocalyptic scenario overall. In addition to this, parasites and hosts might be subject to gene adaption and phenotypic plasticity: temperature resistant genotypes and phenotypes of hosts and parasites might be selected in synchrony through adaptive evolution and thus aid in the sustainability of the host-parasite system ${ }^{65}$. Following this line of thought, future research should consider the possibility and the differences in the adaptation capacity of hosts and parasites considering the difference in generation times and the intraspecific genetic variation ${ }^{42,66}$.

Even though we did not evaluate the final and second intermediate host's performance in this study, trematodes show low specificity towards them and thus may find alternative ways to prosper. A low specificity gives an advantage to the trematode by having different options to complete the life cycle. Taking H. elongata (Mehlis, 1831) as an example, it has several birds as final hosts, such as Larus spp., Haematopus ostralegus, and Somateria mollisima ${ }^{29,50}$. Regarding the infective larval stage released from the final host (i.e., miracidia), no studies are available specifically on $H$. elongata. However, studies conducted using $H$. militaris showed that, although the half-life of miracidia was significantly reduced at 25 and $30^{\circ} \mathrm{C}$ compared to $14^{\circ} \mathrm{C}$, the infectivity of the larvae increased and remained constant at the warmer temperatures ${ }^{67}$. In the case of miracidial eclosion, its proportion increased, and the process was accelerated with increasing temperature $\left(20\right.$ and $\left.30^{\circ} \mathrm{C}\right)$ while it was nil at $12^{\circ} \mathrm{C}^{68}$, altogether suggesting a high tolerance of miracidia to high temperatures. Moreover, regarding the thermal tolerance of the final host, endotherms have the advantage of modulating their body temperature and are highly mobile, thus being capable of seeking shelter in extreme temperature conditions.

In the second intermediate host's case, cercariae usually parasitize M. edulis s.l., but can also infect other bivalves such as the edible cockle Cerastoderma edule ${ }^{29,69,70}$. In addition, trematodes encyst as metacercariaesemi-dormant stages of the parasite-in the second-intermediate host ${ }^{15}$. Although metacercariae are known to negatively affect the host's metabolism, condition index, and biochemistry ${ }^{71-76}$, these larval stages are assumed to pose less stress to the host than rediae, which actively feed on the tissue of the gastropod host ${ }^{15}$. In terms of thermal tolerance, mussels are highly sensitive to thermal exposure and show significant mortality after recurrent heatwave events ${ }^{77}$. Furthermore, since mussels are semi-sessile, they are usually constrained to their habitat and cannot seek shelter as easily as birds or gastropods. However, for infected specimens, recent findings suggest that $H$. elongata metacercarial infections can even protect its host from heat $\left(35^{\circ} \mathrm{C}\right.$ compared to $\left.15^{\circ} \mathrm{C}\right)$ at high infection intensities $\left(>250 \text { metacercariae mussel }^{-1}\right)^{28}$. Although the mechanisms behind this heat-protection are still to be resolved, Selbach et al. ${ }^{28}$ speculate that trematodes might protect the host by pre-equipping it with heat shock proteins.

In summary, by combining multiple traits, we show that the optimal temperature range of parasite performance might be overestimated when looking at individual life cycle components. The thermal sensitivity of the infected gastropod, along with reduced functional lifespan and survival of the cercariae, resulted in a decreased overall performance of the parasite at high temperatures. In addition to this, this study also evaluated the capacity of $H$. elongata cercariae to encyst in the non-host environment as a function of time and temperature for the first time to our knowledge. We determined that increasing temperatures induced faster spontaneous encystment as a consequence of increased cercariae mortality. We show that, as time progresses, the optimal temperature 
for spontaneous encystment shifts towards colder temperatures down to $16^{\circ} \mathrm{C}$, highlighting the importance of time scale in the life cycle of trematodes.

As with every laboratory study, controlled experiments unavoidably neglect other factors important for the thermal tolerance of marine ectotherms and parasite transmission. Predicting the future of trematodes in a warming sea is difficult due to the numerous factors that are related to warming, which can significantly alter host-parasite dynamics. For example, in warming shallow waters, biotic productivity might be greatly increased $^{78}$. Increased biotic productivity can create opportune conditions that invite birds to aggregate, forage, and increase their infection chances ${ }^{79-82}$. This increase in chances of infection will benefit allogenic parasites such as $H$. elongata, which use birds as final hosts ${ }^{79,80}$. On top of this, the thermal sensitivity of infected snails can be buffered by daily thermal fluctuations, which can provide relief to intertidal organisms, especially at extreme temperatures ${ }^{83}$. Moreover, given that temperature can vary within small spatial scales, snails can mobilize to near macro- and micro-habitats with benign temperatures ${ }^{84}$. On the contrary, our experiments restricted snails to constant temperature conditions. Therefore, there is a possibility of an overestimation of the thermal sensitivity of the gastropod. Additionally, parasites can also influence microhabitat selection, especially by trematodes that influence their host's behavior ${ }^{85-87}$. Some trematode species (e.g., Maritrema spp.) can modify the host's behavior so that the host settles in temperatures matching the thermal optimum of the parasite in natural thermal gradients ${ }^{85}$. Therefore, we encourage and highlight the importance of conducting more near-natural experiments on larger scales such as mesocosms and field studies, considering other important factors affecting parasite-host interactions such as salinity, predation, and dilution of free-larval stages ${ }^{16,50,61,88}$.

\section{Methods}

Collection of hosts. The first intermediate host, the gastropod L. littorea, was collected haphazardly by

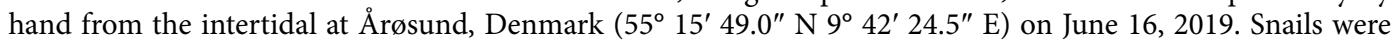
transported immediately in portable coolers to the laboratory and kept in a climate chamber at $16^{\circ} \mathrm{C}$ under a flow-through system of filtered seawater pumped from the Kiel Fjord. Snails were screened for trematode infections by placing one individual per well in 6-well plates filled with $8 \mathrm{~mL}$ of filtered seawater. All wells were covered with transparent lids and placed under lamps for $4 \mathrm{~h}$ to induce emergence of the parasite. Infected and potentially uninfected snails were kept in separate tanks at $16^{\circ} \mathrm{C}$ until the start of the experiment. Snails were fed ad libitum with the seaweed Fucus vesiculosus collected from the Kiel Fjord. The second intermediate host, the blue mussel M. edulis s.l., was collected from the 'Kieler Meeresfarm' aquaculture facility in Kiel, Germany $\left(54^{\circ} 22^{\prime} 59.1^{\prime \prime} \mathrm{N} 10^{\circ} 09^{\prime} 41.8^{\prime \prime} \mathrm{E}\right)$ on May 28,2020 , where no trematode infections have been found after numerous assessments. Mussels were measured, and individuals measuring 30-40 mm were kept in an $8 \mathrm{~L}$ plastic tank filled with filtered seawater at $16^{\circ} \mathrm{C}$. Before starting the experiment, mussels were fed once with $125 \mathrm{ng} / \mathrm{L}$ of chlorella powder (Chlorella vulgaris, Algomed ${ }^{\circ}$ ). To ensure that mussels were uninfected, a sub-sample of 50 mussels was dissected and inspected for metacercarial cysts under a stereo-microscope (Nikon, SMZ1000 body, C-PS160 stand). For a detailed timeline on the collection of hosts and execution of experiments, see Fig. 1.

Experiment 1a: Host survival. Snails were acclimated between June 26 and July 1, 2019, to 4, 10, 16, 22, and $28{ }^{\circ} \mathrm{C}$, respectively, in 5 different thermo-baths by increasing or decreasing temperature by increments/ reductions of $2^{\circ} \mathrm{C}$ every $24 \mathrm{~h}$. This range of temperatures was chosen to cover the range of daily variation in temperatures during summer in shallow waters from the Baltic Sea and the expected critical minimum, maximum and optimal temperatures for the parasite ${ }^{20,34}$. Thieltges and Rick ${ }^{20}$ identified $10-25^{\circ} \mathrm{C}$ as the relevant temperature range for the Baltic trematode species Renicola roscovita. However, since the present study used another trematode species from the Baltic, this range was expanded down to $4{ }^{\circ} \mathrm{C}$ and up to $28{ }^{\circ} \mathrm{C}$ to ensure coverage of the $H$. elongata tolerance range, should significant differences in the thermal tolerance between these trematode species exist. During the acclimation phase, 10 uninfected and 15 infected adult snails per temperature level of similar shell length (Infected: $2.03-2.56 \mathrm{~cm}$; Uninfected: $2.19-2.80 \mathrm{~cm}$ ) were distributed in two 1-L tanks per infection group and fed ad libitum with F. vesiculosus (Fig. 1). More infected snails were used due to the expected trematode-induced mortality under stressful temperatures. Water was constantly aerated and changed three times a week with temperature equilibrated and previously filtered aerated seawater pumped from the Kiel Fjord. After the acclimation period, snails were transferred individually to $50 \mathrm{~mL}$ PLEXIGLAS ${ }^{\circ}$ beakers with $40 \mathrm{~mL}$ of previously aerated and acclimatized filtered seawater pumped from the Kiel Fjord. The photoperiod was set to start of sunrise at 4:00, reaching the maximum experimental intensity of light at 7:00, and sunset starting at 19:00, reaching total darkness at 22:00. Since cercariae are photo-sensitive ${ }^{89}$, we decided to mimic the photoperiod of the season with the highest light intensity in order to avoid underestimations of behavioural responses (i.e., emergence, activity, and infectivity success). Each beaker was covered with a transparent plastic mesh to prevent the snails from escaping. Survival was recorded daily for a total of 17 days. In the case of death, the snail was dissected in order to confirm infection status.

Experiment 1b: Cercarial emergence. In order to evaluate the dependency of cercarial emergence to temperature, water from the Experiment 1a-snails was changed with clean, temperature equilibrated, and previously aerated filtered seawater pumped from the Kiel Fjord. Snails were incubated in recurrent periods of $12 \mathrm{~h}$ during July 2-5, 2019, under artificial light as described for Experiment 1a. After incubation, each beaker (including the ones with uninfected snails) was screened for parasites under the stereo-microscope. Water from the snails that did not shed cercariae was directly replaced with new water. When parasites were spotted, the snail was taken out, and the water was poured into a falcon tube. Afterwards, the beaker was rinsed with $10 \mathrm{~mL}$ of $70 \%$ ethanol and poured again into the falcon tube to fix the cercariae for later counting. The beaker was rinsed once with tap water and once with filtered seawater, filled with $40 \mathrm{~mL}$ of new water and placed back 
with the snails in the thermo-bath for a new incubation period of $12 \mathrm{~h}$. Cercariae were counted under a stereomicroscope (Nikon, SMZ1000 body, C-PS160 stand) by pouring the content of the falcon tube into a petri dish. Metacercariae were also quantified upon appearance. Afterwards, the falcon tube was rinsed with tap water and poured into the petri dish to ensure all cercariae were counted. In total, cercariae were collected every $12 \mathrm{~h}$ over 3 consecutive days. Oxygen levels, salinity, temperature, and $\mathrm{pH}$ were monitored before and after water exchanges. During the incubations, snails were fed with $1 \mathrm{~cm}^{2}$ of F. vesiculosus.

Experiment 2: Cercarial activity. Snails collected on May 21, 2020, from Årøsund, Denmark, were acclimated during May $24-29,2020$, by increasing or decreasing $2^{\circ} \mathrm{C}$ every $24 \mathrm{~h}$. Once the acclimation to the experimental temperatures finished, cercariae were collected on May 30, 2020, by incubating infected snails in 6-well plates filled with $8 \mathrm{~mL}$ of clean temperature equilibrated and aerated seawater at the experimental temperatures $\left(10,16,22\right.$, and $\left.28^{\circ} \mathrm{C}\right)$. Since almost no cercarial emergence occurred at $4{ }^{\circ} \mathrm{C}$, this temperature was not included in the Experiment 2 and 3. After $1 \mathrm{~h}$ of incubation of snails under full light stimulus at the acclimation temperatures, fully active cercariae released by $8-12$ snails were pooled together to include potential variation in thermal sensitivity among clones ${ }^{90}$. After collection, cercariae were immediately distributed in 12 PLEXIGLAS ${ }^{\circ}$ beakers (10 cercariae in each beaker) filled with $40 \mathrm{~mL}$ of aerated, temperature equilibrated and filtered seawater (Fig. 1). The beakers were distributed between two thermo-baths per temperature level ( 6 beakers per thermo-bath). The photoperiod resembled the one described for Experiment 1a. During the first $24 \mathrm{~h}$, the activity of cercariae was recorded every $2 \mathrm{~h}$. After the first $24 \mathrm{~h}$, cercariae were evaluated every $24 \mathrm{~h}$ until all cercariae were dead or encysted. Activity traits included self-propelling capacity, premortem encystment, and mortality. "Self-propelling capacity" or functional lifespan was defined as cercariae which were swirling and displacing themselves in the water. "Premortem encystment" is the encystment of cercariae without the presence of the second intermediate host, which was identified by the formation of a defined opalescent cyst inside which the larvae could move ${ }^{15}$. Cercariae were categorized as "dead" when no movement was detected for $15 \mathrm{~s}$ after mechanical stimulus with a thin needle. In order to monitor water parameters (salinity, temperature, $\mathrm{pH}$, and dissolved oxygen) without disturbing the cercariae with the multimeter probe (WTW 3630 IDS, Kaiserslautern, Germany), an additional seawater filled beaker per thermo-bath was added.

Experiment 3: Cercarial infectivity. Infectivity of $H$. elongata was performed as described in Bommarito et al. ${ }^{61}$. In brief, on June 1, 2020, 10 mussels (M. edulis s.l.) per temperature measuring 30-40 mm of length were distributed among $50 \mathrm{~mL}$ PLEXIGLAS ${ }^{\circ}$ beakers, each filled with $40 \mathrm{~mL}$ of aerated, temperature equilibrated, and filtered seawater (Fig. 1). Each set of ten beakers (with mussels), were distributed between two thermo-baths (5 beakers per thermo-bath) previously set to the experimental temperatures $\left(10,16,22\right.$ or $\left.28^{\circ} \mathrm{C}\right)$. The same photoperiod described for Experiment la was used. Before offering the cercariae to the mussels, $2 \mathrm{~mL}$ of a chlorella powder solution $\left(2.50 \mu \mathrm{g} / \mathrm{L} ;\right.$ C. vulgaris, Algomed $\left.{ }^{\circ}\right)$ was added to each beaker (final concentration: $100 \mathrm{ng} / \mathrm{L}$ ) to induce mussel filtering. From the same set of snails acclimatized in Experiment 2, cercariae were collected applying the same approach as described for Experiment 2. Nevertheless, since a significant number of snails died in the $28^{\circ} \mathrm{C}$ treatment, the minimal number of snails possible $(n=4)$ was used for cercariae collection in all treatments. After cercariae collection, 20 fully active cercariae were pipetted in each beaker as close as possible to the mussel inhalant siphon. They were then incubated for $24 \mathrm{~h}$ to ensure complete cercarial encystment ${ }^{91}$. Mussels were removed from the experimental containers and kept at $-80^{\circ} \mathrm{C}$ until infection intensity evaluation. The intensity of infection was evaluated by counting metacercariae in whole soft body squash preparations under a stereo-microscope (Nikon, SMZ1000 body, C-PS160 stand).

Statistical analyses. All analyses were performed in R (version 4.0.2), RStudio@ 1.3.1073 (2009-2020 RStudio, PBC). For Experiment 1a, the significance of differences between the means of infected and uninfected hosts' survival in each temperature was tested with a Mann-Whitney-U test with Holm-corrected p-values. The variance of gross cercarial emergence, encystment proportion, and net cercarial emergence was modeled in response to temperature as a continuous predictor. For cercarial emergence (Experiment 1b), a generalized linear model was applied with Poisson distribution and a second-degree polynomial term (considering the complex nonlinear effect of temperature) using the "glm" function from the "stats" package. The assumption of residual independence was tested by inspecting response (ordinary residuals, $y_{i}-\mu_{i}$ ), deviance, Pearson, and scaledPearson residuals against predicted values and temperature ${ }^{92}$. However, since over-dispersion was detected, a correction to the standard errors was performed using a quasi-GLM model ${ }^{92}$. For the proportion of encysted cercariae per snail, over-dispersion was also detected. In this case, a negative binomial GLM was chosen over a quasi-GLM with Poisson distribution based on the log-likelihood test and the dispersion parameter ${ }^{92}$. Net cercarial emergence was calculated based on a hypothetical population of 10 snails using Eq. 1.

$$
N_{E, x}=n \times E_{i, x} \times p_{S, x},
$$

where $N_{E, x}$ is the net cercarial emergence (\# cercariae emerged from survived snails at temperature $x$ ); $n$ is the number of snails in a population (here, assumed to be 10); $E_{i, x}$ is the \# cercariae emerged per snail (replicate i) at temperature $x ; p_{S, x}$ is the snails survival probability at temperature $x$. Although it is known that cercarial emergence rate can change over time ${ }^{61,89}$, we assume that the emergence per individual in this case represent the natural variability in emergence patterns since snails were naturally infected and are, therefore, not synchronized.

The variation in net cercarial emergence was modeled using a generalized linear model with zero-inflated negative binomial distribution with linear parametrization and a third-degree polynomial term with the function "glmmTMB" from the "glmmTMB" package ${ }^{93}$. Model suitability was evaluated using the residual diagnostics tool from the "DHARMa" package ${ }^{94}$, which includes quantile-quantile plots with KS test, outlier and dispersion as 
added tests, and a residual plot against predicted values with a built-in quantile regression to detect deviations from normality ${ }^{94}$.

Variations in the proportion of active, dead and encysted cercariae (evaluated in Experiment 2) were modeled as functions of time and temperature as continuous variables using general and generalized additive mixed models (GAMM) with restricted maximum likelihood (REML) as fitting method using the "gam" function from the "mgcv" package ${ }^{95,96}$. GAMMs were selected over GLMMs to allow for the needed flexibility in modeling the variance in the response; the response variables varied differently and non-linearly along time in different temperature treatments, specially encystment rates. A binomial distribution with weights on the number of cercariae per beaker was used for modeling cercarial self-propelling and mortality, and a gaussian distribution was used for cercarial encystment. Temperature and time were included as smooth terms and their interaction as a tensor product (i.e., non-isotropic smooth), which allows the modeling of an interaction between variables in different units such as time and temperature ${ }^{95}$. The attributes "thermobath" and "sample id" were included as random (intercept) effects in the global models and time as AR-1 autocorrelation structure to correct for potential dependency in the residuals along time. Model validation was performed by the "gam.check" function from the "mgcv" package and evaluating the residuals histogram plots and boxplots of residuals against each term. All global GAMM models were reduced to having only "sample id" as random factor since the random effects from "thermobath" were not significant. Since no among-residual dependency along time was detected for cercarial self-propelling and mortality (Fig. 4A,B), no autocorrelation structure was included in the models. In the case of cercarial encystment (Fig. 4C), temporal autocorrelation was detected and was therefore corrected for in the model. For cercariae self-propelling capacity the effective time when $50 \%$ of the response was reached $\left(\mathrm{ET}_{50}\right)$ was calculated with imageJ based on the plotted model estimates against time. A similar approach was taken to calculate the half-life or lethal time when $50 \%$ of the cercariae were dead $\left(\mathrm{LT}_{50}\right)$.

For experiment 3 , the variation in infection success as a function of temperature was modelled as a continuous variable using GAMM with REML as fitting method. Temperature was included as a smooth term and thermobath as a random (intercept) effect. GAMM was selected over GLMM because it offered the best compromise between model performance and biological plausibility. Model suitability was evaluated using the residual diagnostics tool from the "DHARMa package". Net cercarial infectivity was calculated using the Eq. (2).

$$
N_{I, x}=\overline{N_{E, x}} \times I_{i, x}
$$

where $N_{I, x}$ is the net infectivity (\# infective cercariae adjusted to the proportion of survived snails per temperature at temperature $x$ ); $\overline{N_{E, x}}$ is the mean net cercarial emergence at temperature $x$ (estimated from the corresponding GLM model); $I_{i, x}$ is the infection success (replicate $i$ ) at temperature $x$.

The variation in net infectivity as a response to temperature was modeled using a generalized linear model with a third-degree polynomial term, thermobath as random factor and zero-inflated negative binomial distribution with linear parametrization using the "glmmTMB" function. Model suitability was evaluated using the residual diagnostics tool from the "DHARMa" package.

For all models (with the exception of zero-inflated models) marginal and conditional R-squares were extracted using the "r.squaredGLMM" function of the "MuMIn" package ${ }^{97}$. For models with a log-link function the trigamma method was used to calculate pseudo- $\mathrm{R}^{2}$ and for binomial distribution theoretical pseudo- $\mathrm{R}^{2}$ was used $^{98}$. For zero-inflated models, $\mathrm{R}^{2}$ were extracted with the function " $\mathrm{r} 2$ _zeroinflated" from the "performance" package $^{99}$. Optimal temperatures for gross and net cercarial emergence, and gross and net infectivity of cercariae were estimated from the respective models using the function "predict" from the "car" package ${ }^{100}$. The normality of distributions was tested through a Shapiro-Wilk test and further evaluated with histograms and boxplots.

In order to be able to compare among the measured response variables or trematode performance traits at different temperatures, the logarithmic response ratio was calculated in relation to the mean response from the control temperature of $16^{\circ} \mathrm{C}$. The means of the control temperature for each trait were estimated from the above-described models. This was performed according to Lajeunesse ${ }^{35}$, who developed an adjustment to the widely used response ratio described by Hedges et al. ${ }^{101}$. The adjustment procures the avoidance of biases from small sample sizes $(\mathrm{n}<15)$. To this matter, Eq. (3) was applied.

$$
R R^{\Delta}=\ln \left(\frac{X_{T}}{\bar{X}_{C}}\right)+\frac{1}{2}\left[\frac{\left(S D_{T}\right)^{2}}{N_{T} \bar{X}_{T}^{2}}-\frac{\left(S D_{C}\right)^{2}}{N_{C} \bar{X}_{C}^{2}}\right],
$$

where $N_{T / C}$ is the sample size in treatment/control; $R R^{\Delta}$ is the adjusted log response ratio; $S D_{T / C}$ is the standard deviation of treatment/control sample; $\bar{X}_{C / T}$ is the estimated mean response of control/treatment; $X_{T}$ is the response of a sample from a treatment.

Next to the log ratio, Lajeunesse ${ }^{35}$ recommends the employment of a small-sample size adjusted Geary index for both the control and treatment groups as diagnostic tool to validate log response ratios. The adjusted Geary index can be checked using the Eq. (4).

$$
\frac{\bar{X}}{S D} \sqrt{N} \geq 3
$$

\section{Data availability}

All of the data that support the findings of this study are available from the corresponding author on reasonable request. 
Received: 7 October 2021; Accepted: 3 January 2022

Published online: 21 January 2022

\section{References}

1. Harley, C. D. G. et al. The impacts of climate change in coastal marine systems. Ecol. Lett. 9, 228-241 (2006).

2. Poloczanska, E. S. et al. Global imprint of climate change on marine life. Nat. Clim. Change 3, 919-925 (2013).

3. Hoegh-Guldberg, O. et al. Impacts of $1.5^{\circ} \mathrm{C}$ global warming on natural and human systems. In: [...]. in Global Warming of $1.5^{\circ} \mathrm{C}$. An IPCC Special Report on the Impacts of Global Warming of $1.5^{\circ} \mathrm{C}$ Above Preindustrial Levels and Related Global Greenhouse Gas Emission Pathways, in the Context of Strengthening the Global Response to the Threat of Climate Change (eds. Masson-Delmotte, V. et al.) 175-311 (2018)

4. Gunderson, A. R., Armstrong, E. J. \& Stillman, J. H. Multiple stressors in a changing world: The need for an improved perspective on physiological responses to the dynamic marine environment. Ann. Rev. Mar. Sci. 8, 357-378 (2016).

5. Ban, S. S., Graham, N. A. J. \& Connolly, S. R. Evidence for multiple stressor interactions and effects on coral reefs. Glob. Change Biol. 20, 681-697 (2014).

6. Marcogliese, D. J. The impact of climate change on the parasites and infectious diseases of aquatic animals. OIE Rev. Sci. Tech. 27, 467-484 (2008).

7. Urban, M. C., Tewksbury, J. J. \& Sheldon, K. S. On a collision course: Competition and dispersal differences create no-analogue communities and cause extinctions during climate change. Proc. R. Soc. B Biol. Sci. 279, 2072-2080 (2012).

8. Mouritsen, K. N. \& Poulin, R. Parasitism, climate oscillations and the structure of natural communities. Oikos 97, 462-468 (2002).

9. Poulin, R. \& Mouritsen, K. N. Climate change, parasitism and the structure of intertidal ecosystems. J. Helminthol. 80, 183-191 (2006).

10. Mouritsen, K. N., Sørensen, M. M., Poulin, R. \& Fredensborg, B. L. Coastal ecosystems on a tipping point: Global warming and parasitism combine to alter community structure and function. Glob. Change Biol. 24, 4340-4356 (2018).

11. James, C. C. et al. Marine host-pathogen dynamics: Influences of global climate change. Oceanography 31, 182-193 (2018).

12. Friesen, O. C., Poulin, R. \& Lagrue, C. Temperature and multiple parasites combine to alter host community structure. Oikos 130(9), 1500-1511 (2021).

13. Poulin, R. Parasite biodiversity revisited: Frontiers and constraints. Int. J. Parasitol. 44, 581-589 (2014).

14. Kuris, A. M. et al. Ecosystem energetic implications of parasite and free-living biomass in three estuaries. Nature 454, 515-518 (2008).

15. Galaktionov, K. V. \& Dobrovolskij, A. A. The Biology and Evolution of Trematodes: An Essay on the Biology, Morphology, Life Cycles, Transmissions, and Evolution of Digenetic Trematodes. The American Journal of Semiotics vol. 4 (Springer-Science+Business Media Dordrecht, 2003).

16. Thieltges, D. W., Jensen, K. T. \& Poulin, R. The role of biotic factors in the transmission of free-living endohelminth stages. Parasitology 135, 407-426 (2008).

17. Pietrock, M. \& Marcogliese, D. J. Free-living endohelminth stages: At the mercy of environmental conditions. Trends Parasitol. 19, 293-299 (2003).

18. Morley, N. J. Thermodynamics of cercarial survival and metabolism in a changing climate. Parasitology 138, 1442-1452 (2011).

19. Poulin, R. Global warming and temperature-mediated increases in cercarial emergence in trematode parasites. Parasitology 132, 143-151 (2006).

20. Thieltges, D. W. \& Rick, J. Effect of temperature on emergence, survival and infectivity of cercariae of the marine trematode Renicola roscovita (Digenea: Renicolidae). Dis. Aquat. Organ. 73, 63-68 (2006).

21. Selbach, C. \& Poulin, R. Some like it hotter: Trematode transmission under changing temperature conditions. Oecologia 194, $745-755$ (2020).

22. Morley, N. J. Inbred laboratory cultures and natural trematode transmission under climate change. Trends Parasitol. 27, 286-287 (2011).

23. Paull, S. H. \& Johnson, P. T. J. Experimental warming drives a seasonal shift in the timing of host-parasite dynamics with consequences for disease risk. Ecol. Lett. 17, 445-453 (2014)

24. Paull, S. H., Lafonte, B. E. \& Johnson, P. T. J. Temperature-driven shifts in a host-parasite interaction drive nonlinear changes in disease risk. Glob. Change Biol. 18, 3558-3567 (2012).

25. Studer, A., Poulin, R. \& Tompkins, D. M. Local effects of a global problem: Modelling the risk of parasite-induced mortality in an intertidal trematode-amphipod system. Oecologia 172, 1213-1222 (2013).

26. Studer, A., Thieltges, D. W. \& Poulin, R. Parasites and global warming: Net effects of temperature on an intertidal host-parasite system. Mar. Ecol. Prog. Ser. 415, 11-22 (2010).

27. Mouritsen, K. N., Tompkins, D. M. \& Poulin, R. Climate warming may cause a parasite-induced collapse in coastal amphipod populations. Oecologia 146, 476-483 (2005).

28. Selbach, C., Barsøe, M., Vogensen, T. K., Samsing, A. B. \& Mouritsen, K. N. Temperature-parasite interaction: Do trematode infections protect against heat stress?. Int. J. Parasitol. 50, 1189-1194 (2020).

29. Werding, B. Morphologie, Entwicklung und Ökologie digener Trematoden-Larven der Strandschnecke Littorina littorea. Mar. Biol. 3, 306-333 (1969).

30. Somero, G. N. The physiology of climate change: How potentials for acclimatization and genetic adaptation will determine 'winners' and 'losers'. J. Exp. Biol. 213, 912-920 (2010).

31. Fredensborg, B. L., Mouritsen, K. N. \& Poulin, R. Impact of trematodes on host survival and population density in the intertidal gastropod Zeacumantus subcarcinatus. Mar. Ecol. Prog. Ser. 290, 109-117 (2005).

32. Morón Lugo, S. C. et al. Warming and temperature variability determine the performance of two invertebrate predators. Sci. Rep. 10, 1-14 (2020).

33. Wolf, F. et al. High resolution water temperature data between January 1997 and December 2018 at the GEOMAR pier surface. Bremen PANGAEA. https://doi.org/10.1594/PANGAEA.919186 (2020).

34. Franz, M., Lieberum, C., Bock, G. \& Karez, R. Environmental parameters of shallow water habitats in the SW Baltic Sea. Earth Syst. Sci. Data 11, 947-957 (2019).

35. Lajeunesse, M. J. Bias and correction for the log response ratio in ecological meta-analysis. Ecology 96, 2056-2063 (2015).

36. Gräwe, U., Friedland, R. \& Burchard, H. The future of the western Baltic Sea: Two possible scenarios. Ocean Dyn. 63, 901-921 (2013).

37. Pansch, C. et al. Heat waves and their significance for a temperate benthic community: A near-natural experimental approach. Glob. Change Biol. 24, 4357-4367 (2018).

38. Sokolova, I. M., Frederich, M., Bagwe, R., Lannig, G. \& Sukhotin, A. A. Energy homeostasis as an integrative tool for assessing limits of environmental stress tolerance in aquatic invertebrates. Mar. Environ. Res. 79, 1-15 (2012).

39. Clarke, A. P., Mill, P. J. \& Grahame, J. The nature of heat coma in Littorina littorea (Mollusca: Gastropoda). Mar. Biol. 137, 447-451 (2000).

40. McDaniel, S. J. Littorina littorea: Lowered heat tolerance due to Cryptocotyle lingua. Exp. Parasitol. 25, 13-15 (1969). 
41. Ataev, G. Temperature influence on the development and biology of rediae and cercariae of Philophthalmus rhionica (Trematoda). Parazitologiâ 25, 349-359 (1991).

42. Paull, S. H. \& Johnson, P. T. J. High temperature enhances host pathology in a snail-trematode system: Possible consequences of climate change for the emergence of disease. Freshw. Biol. 56, 767-778 (2011).

43. Paull, S. H., Raffel, T. R., Lafonte, B. E. \& Johnson, P. T. J. How temperature shifts affect parasite production: Testing the roles of thermal stress and acclimation. Funct. Ecol. 29, 941-950 (2015).

44. Kuris, A. M. Effect of exposure to Echinostoma liei miracidia on growth and survival of young Biomphalaria glabrata snails. Int. J. Parasitol. 10, 303-308 (1980).

45. Mouritsen, K. N. \& Haun, S. C. B. Community regulation by herbivore parasitism and density: Trait-mediated indirect interactions in the intertidal. J. Exp. Mar. Biol. Ecol. 367, 236-246 (2008).

46. Bommarito, C. et al. Effects of first intermediate host density, host size and salinity on trematode infections in mussels of the south-western Baltic Sea. Parasitology 148, 486-494 (2021).

47. McCarthy, A. M. The influence of temperature on the survival and infectivity of the cercariae of Echinoparyphium recurvatum (Digenea: Echinostomatidae). Parasitology 118, 383-388 (1999).

48. Morley, N. J. \& Lewis, J. W. Thermodynamics of trematode infectivity. Parasitology 142, 585-597 (2015).

49. Mouritsen, K. N. \& Jensen, K. T. Parasite transmission between soft-bottom invertebrates: Temperature mediated infection rates and mortality in Corophium volutator. Mar. Ecol. Prog. Ser. 151, 123-134 (1997).

50. de Montaudouin, X., Wegeberg, A. M., Jensen, K. T. \& Sauriau, P. G. Infection characteristics of Himasthla elongata cercariae in cockles as a function of water current. Dis. Aquat. Organ. 34, 63-70 (1998).

51. Vajedsamiei, J. et al. Simultaneous recording of filtration and respiration in marine organisms in response to short-term environmental variability. Limnol. Oceanogr. Methods https://doi.org/10.1002/lom3.10414 (2021).

52. Koehler, A. V., Brown, B., Poulin, R., Thieltges, D. W. \& Fredensborg, B. L. Disentangling phylogenetic constraints from selective forces in the evolution of trematode transmission stages. Evol. Ecol. 26, 1497-1512 (2012).

53. Stunkard, H. W. The morphology and life history of the digenetic trematode, Himasthla littorinae sp. n. (Echinostomatidae). J. Parasitol. 52, 367-372 (2014).

54. Selbach, C. \& Poulin, R. Parasites in space and time: A novel method to assess and illustrate host-searching behaviour of trematode cercariae. Parasitology 145, 1469-1474 (2018).

55. Gorbushin, A. M. \& Levakin, I. A. Encystment in vitro of the cercariae Himasthla elongata (Trematoda: Echinostomatidae). J. Evol. Biochem. Physiol. 41, 428-436 (2005).

56. Gorbushin, A. M. \& Shaposhnikova, T. G. In vitro culture of the avian echinostome Himasthla elongata: From redia to marita. Exp. Parasitol. 101, 234-239 (2002).

57. Levakin, I. A., Losev, E. A., Nikolaev, K. E. \& Galaktionov, K. V. In vitro encystment of Himasthla elongata cercariae (Digenea, Echinostomatidae) in the haemolymph of blue mussels Mytilus edulis as a tool for assessing cercarial infectivity and molluscan susceptibility. J. Helminthol. 87, 180-188 (2013).

58. Choisy, M., Brown, S. P., Lafferty, K. D. \& Thomas, F. Evolution of trophic transmission in parasites: Why add intermediate hosts?. Am. Nat. 162, 172-181 (2003).

59. Pechenik, J. \& Fried, B. Effect of temperature on survival and infectivity of Echinostoma trivolvis cercariae: A test of the energy limitation hypothesis. Parasitology 111, 373-378 (1995).

60. Fried, B. \& Ponder, E. L. Effects of temperature on survival, infectivity and in vitro encystment of the cercariae of Echinostoma caproni. J. Helminthol. 77, 235-238 (2003).

61. Bommarito, C. et al. Freshening rather than warming drives trematode transmission from periwinkles to mussels. Mar. Biol. $167,1-12(2020)$.

62. Morley, N. J. \& Lewis, J. W. Thermodynamics of cercarial development and emergence in trematodes. Parasitology 140, 121-1214 (2013).

63. Büttger, H. et al. Community dynamics of intertidal soft-bottom mussel beds over two decades. Helgol. Mar. Res. 62, 23-36 (2008).

64. Jaatinen, K., Westerbom, M., Norkko, A., Mustonen, O. \& Koons, D. N. Detrimental impacts of climate change may be exacerbated by density-dependent population regulation in blue mussels. J. Anim. Ecol. 90, 562-573 (2021).

65. Studer, A. \& Poulin, R. Analysis of trait mean and variability versus temperature in trematode cercariae: Is there scope for adaptation to global warming?. Int. J. Parasitol. 44, 403-413 (2014).

66. Berkhout, B. W., Lloyd, M. M., Poulin, R. \& Studer, A. Variation among genotypes in responses to increasing temperature in a marine parasite: Evolutionary potential in the face of global warming?. Int. J. Parasitol. 44, 1019-1027 (2014).

67. Vanoverschelde, R. Studies on the life-cycle of Himasthla militaris (Trematoda: Echinostomatidae): Influence of salinity and temperature on egg development and miracidial emergence. Parasitology 82, 459-465 (1981).

68. Vanoverschelde, R. Studies on the life-cycle of Himasthla militaris (Trematoda: Echinostomatidae): Influence of temperature and salinity on the life-span of the miracidium and the infection of the first intermediate host, Hydrobia ventrosa. Parasitology 84, 131-135 (1982).

69. de Montaudouin, X. et al. Digenean trematode species in the cockle Cerastoderma edule: Identification key and distribution along the North-Eastern Atlantic Shoreline. J. Mar. Biol. Assoc. U.K. 89, 543-556 (2009).

70. Richard, A., de Montaudouin, X., Rubiello, A. \& Maire, O. Cockle as second intermediate host of trematode parasites: Consequences for sediment bioturbation and nutrient fluxes across the benthic interface. J. Mar. Sci. Eng. 9, 749 (2021).

71. Magalhães, L., Freitas, R. \& de Montaudouin, X. How costly are metacercarial infections in a bivalve host? Effects of two trematode species on biochemical performance of cockles. J. Invertebr. Pathol. 177, 107479 (2020).

72. Magalhães, L., de Montaudouin, X., Figueira, E. \& Freitas, R. Trematode infection modulates cockles biochemical response to climate change. Sci. Total Environ. 637-638, 30-40 (2018).

73. Magalhães, L. et al. Seasonal variation of transcriptomic and biochemical parameters of cockles (Cerastoderma edule) related to their infection by trematode parasites. J. Invertebr. Pathol. 148, 73-80 (2017).

74. Bakhmet, I., Nikolaev, K. \& Levakin, I. Effect of infection with Metacercariae of Himasthla elongata (Trematoda: Echinostomatidae) on cardiac activity and growth rate in blue mussels (Mytilus edulis) in situ. J. Sea Res. 123, 51-54 (2017).

75. Stier, T., Drent, J. \& Thieltges, D. W. Trematode infections reduce clearance rates and condition in blue mussels Mytilus edulis. Mar. Ecol. Prog. Ser. 529, 137-144 (2015).

76. de Montaudouin, X., Bazairi, H. \& Culloty, S. Effect of trematode parasites on cockle Cerastoderma edule growth and condition index: A transplant experiment. Mar. Ecol. Prog. Ser. 471, 111-121 (2012).

77. Seuront, L., Nicastro, K. R., Zardi, G. I. \& Goberville, E. Decreased thermal tolerance under recurrent heat stress conditions explains summer mass mortality of the blue mussel Mytilus edulis. Sci. Rep. 9, 1-14 (2019).

78. Österblom, H. et al. Human-induced trophic cascades and ecological regime shifts in the baltic sea. Ecosystems 10, 877-889 (2007).

79. Zander, C. D. \& Reimer, L. W. Parasitism at the ecosystem level in the Baltic Sea. Parasitology 124, 119-135 (2002).

80. Johnson, P. T. J. et al. Aquatic eutrophication promotes pathogenic infection in amphibians. Proc. Natl. Acad. Sci. U. S. A. 104, 15781-15786 (2007). 
81. Budria, A. \& Candolin, U. How does human-induced environmental change influence host-parasite interactions?. Parasitology 141, 462-474 (2014).

82. Aalto, S. L., Decaestecker, E. \& Pulkkinen, K. A three-way perspective of stoichiometric changes on host-parasite interactions. Trends Parasitol. 31, 333-340 (2015).

83. Vajedsamiei, J., Melzner, F., Raatz, M., Moron, S. \& Pansch, C. Cyclic thermal fluctuations can be burden or relief for an ectotherm depending on fluctuations' average and amplitude. Funct. Ecol. 35, 2483-2496 (2021).

84. Moisez, E., Spilmont, N. \& Seuront, L. Microhabitats choice in intertidal gastropods is species-, temperature- and habitat-specific. J. Therm. Biol. 94, 102785 (2020).

85. Bates, A. E., Leiterer, F., Wiedeback, M. L. \& Poulin, R. Parasitized snails take the heat: A case of host manipulation?. Oecologia 167, 613-621 (2011).

86. Shinagawa, K., Urabe, M. \& Nagoshi, M. Relationships between trematode infection and habitat depth in a freshwater snail, Semisulcospira libertina (Gould). Hydrobiologia 397, 171-178 (1999).

87. Friesen, O. C., Poulin, R. \& Lagrue, C. Parasite-mediated microhabitat segregation between congeneric hosts. Biol. Lett. 14, 20170671 (2018).

88. Welsh, J. E., Van Der Meer, J., Brussaard, C. P. D. \& Thieltges, D. W. Inventory of organisms interfering with transmission of a marine trematode. J. Mar. Biol. Assoc. U.K. 94, 697-702 (2014).

89. Soldánová, M., Selbach, C. \& Sures, B. The early worm catches the bird? Productivity and patterns of Trichobilharzia szidati cercarial emission from Lymnaea stagnalis. PLoS One 11, 1-21 (2016).

90. Solovyeva, A. et al. Reduced infectivity in Himasthla elongata (Trematoda, Himasthlidae) cercariae with deviant photoreaction. J. Helminthol. 94, 1-5 (2020).

91. de Montaudouin, X., Blanchet, H., Desclaux-Marchand, C., Lavesque, N. \& Bachelet, G. Cockle infection by Himasthla quissetensis-I. From cercariae emergence to metacercariae infection. J. Sea Res. 113, 99-107 (2016).

92. Zuur, A. F., Ieno, E. N., Walker, N. J., Saveliev, A. A. \& Smith, G. M. Mixed Effects Models and Extensions in Ecology with R. Statistics for Biology and Health vol. 36 (Springer, 2009).

93. Brooks, M. E. et al. glmmTMB balances speed and flexibility among packages for zero-inflated generalized linear mixed modeling. RJ. 9, 378-400 (2017).

94. Hartig, F. DHARMa: Residual Diagnostics for Hierarchical (Multi-Level/Mixed) Regression Models. R package version 0.2.0. (2018).https://CRAN.R-project.org/package=DHARMa 1-36 https://cran.r-project.org/web/packages/DHARMa/DHARMa. pdf. Accessed 26 Feb 2021.

95. Wood, S. N. Generalized Additive Models: An Introduction with R 2nd edn. (CRC, 2017).

96. Wood, S. N., Pya, N. \& Säfken, B. Smoothing parameter and model selection for general smooth models. J. Am. Stat. Assoc. 111, $1548-1563$ (2016)

97. Nakagawa, S. \& Schielzeth, H. A general and simple method for obtaining $\mathrm{R}^{2}$ from generalized linear mixed-effects models. Methods Ecol. Evol. 4, 133-142 (2013).

98. Nakagawa, S., Johnson, P. C. D. \& Schielzeth, H. The coefficient of determination $\mathrm{R}^{2}$ and intra-class correlation coefficient from generalized linear mixed-effects models revisited and expanded. J. R. Soc. Interface 14, 1-11 (2017).

99. Lüdecke, D., Makowski, D., Waggoner, P. \& Patil, I. Assessment of Regression Models Performance. CRAN. CRAN https://easys tats.github.io/performance/ (2020) https://doi.org/10.1098/rsif.2017.0213. Accessed 1 Sept 2021.

100. Fox, J. \& Weisberg, S. An R Companion to Applied Regression. Robust Regression in R (Sage, 2019).

101. Hedges, L. V., Gurevitch, J. \& Curtis, P. S. The meta-analysis of response ratios in experimental ecology. Ecology 80, 1150-1156 (1999).

\section{Acknowledgements}

We would like to thank Maral Khosravi for her kind assistance in the field and trematode identification. We are also grateful to Björn Buchholz and Renate Schütt for their valuable technical and scientific input. We also extend our gratitude to Dr. Tim Staufenberger and Nikolai Nissen from the Kieler Meeresfarm for providing the mussels. This study was funded by BMBF/PTJ (Federal Ministry of Education and Research, Germany, grant 03F0821A, PI Wahl and grant 03F0821B, PI B Sures, and the BMBF/MOST grant 3-15216, PI G Rilov). Opinions, findings, conclusions and recommendations expressed in this publication are that of the authors, and the BMBF/ PTJ accepts no liability whatsoever in this regard.

\section{Author contributions}

The following authors contributed to the conception or design of the work: D.M.D.M., C.B., B.S.; data acquisition and analysis: D.M.D.M., C.B., J.V.; data interpretation: D.M.D.M., C.B., J.V., D.G., G.R., M.W., B.S.; manuscript writing or revision: D.M.D.M., C.B., J.V., D.G., G.R., M.W., B.S.

\section{Funding}

Open Access funding enabled and organized by Projekt DEAL.

\section{Competing interests}

The authors declare no competing interests.

\section{Additional information}

Supplementary Information The online version contains supplementary material available at https://doi.org/ 10.1038/s41598-022-05139-5.

Correspondence and requests for materials should be addressed to D.M.D.-M.

Reprints and permissions information is available at www.nature.com/reprints.

Publisher's note Springer Nature remains neutral with regard to jurisdictional claims in published maps and institutional affiliations. 
(c) (i) Open Access This article is licensed under a Creative Commons Attribution 4.0 International cc) License, which permits use, sharing, adaptation, distribution and reproduction in any medium or format, as long as you give appropriate credit to the original author(s) and the source, provide a link to the Creative Commons licence, and indicate if changes were made. The images or other third party material in this article are included in the article's Creative Commons licence, unless indicated otherwise in a credit line to the material. If material is not included in the article's Creative Commons licence and your intended use is not permitted by statutory regulation or exceeds the permitted use, you will need to obtain permission directly from the copyright holder. To view a copy of this licence, visit http://creativecommons.org/licenses/by/4.0/.

(C) The Author(s) 2022 